informative. There is some repetition in Harcourt and Stewart's because it is written as a reference work; extensive cross-referencing and helpful section headings make it easy to use. Maestripieri's slimmer volume will appeal to a general audience with its fast pace, references to popular culture and wide-ranging discussion of human behaviour. It cites the original studies, but could leave primatologists wishing for more in-depth discussion.

Just as we are on the brink of a more nuanced and thorough understanding of primate and human society, the breakdown of human society continues to fuel the demise of the remaining strongholds of primates in the wild. For

\title{
Taxonomy on trial
}

\section{Trying Leviathan: The Nineteenth- Century New York Court Case That Put a Whale on Trial and Challenged the Order of Nature \\ by D. Graham Burnett \\ Princeton University Press: 2007. 304 pp. $\$ 29.95, \notin 17.95$}

\section{Henry Nicholls}

When the Catholic Church put Galileo on trial for his heretic views, man's position in the Universe was at stake. When schoolteacher John Scopes entered a Tennessee courtroom in 1925 for violating the state's anti-evolution statute, the issue was man's relationship to the animal kingdom. It's hard to imagine that a case brought by a Manhattan fish-oil inspector against a purveyor of whale oil could end up in similar territory. As D. Graham Burnett's enthralling book demonstrates, it did just that.

Trying Leviathan chronicles a courtroom drama that gripped New York in 1818: the case of Maurice v. Judd. Earlier that year, the state had introduced a law obliging those selling 'fish oils' to have their casks inspected and certified. It was hoped that this would raise the bar for a product often diluted with sediment and dirty water. For James Maurice, New York City's inspector of fish oils, whale oil was part of his remit. Traders such as Samuel Judd, head of the New York Spermaceti Oil and Candle factory, begged to differ and put the law to the test.

The ensuing legal tussle had to settle the superficially simple question of whether whale oil was fish oil and therefore liable for inspection. Burnett, a historian of science at Princeton University, shows it did far more - fuelling a sensational public debate that put the order of nature, and how we know it, in the dock. The impact of this case may, in part, explain why thinkers such as William Whewell and John Stuart Mill applied their minds to precisely this problem of whether a whale is a fish, and why Herman Melville's Ishmael pondered the question in Moby-Dick. instance, gorillas are now listed as critically endangered by the World Conservation Union (Nature 449, 127; 2007).

Contrary to his stereotype, Machiavelli believed that force should be mitigated with prudence, that morality must not be abandoned. Where is our prudence and morality when we ignore the fate of other peoples and species who share our planet? Humans should find a way to narrow the gap between our own well-being and that of our fellow creatures. Sarah F. Brosnan is an assistant professor in the Department of Psychology, Georgia State 5010, USA. University, PO Box 5010, Atlanta, Georgia 30302-

Burnett scrutinizes the central whale/fish conundrum from the four main perspectives of the time: laymen, natural philosophers, whalers and businessmen. This conjures up a rich and rounded vision of life in the young republic. He brings New York and the packed courtroom alive, characterizes the state of scientific knowledge at this interesting moment in the history of natural history, cuts deep into cetacean flesh, and steps into the wheeling, dealing commercial world of downtown Manhattan.

Two characters take centre stage in the trial: distinguished naturalist Samuel Latham Mitchill and prosecution lawyer William Sampson. As the star witness for the defence, Mitchill brought the latest science into the courtroom, using linnean taxonomy and state-of-the-art Cuvierian comparative anatomy to make the case for the whale as a mammal. Sampson mugged up on his history of science, and his cross-examination of Mitchill is an awesome display of eloquence and wit. Trying Leviathan is worth reading if only for the extraordinary exchange between these men.

Mitchill's faith in comparative anatomy painted an enlightened picture of whales to the jury - viviparous, lactating beasts with complex hearts, lungs and livers. Sampson countered by satirizing the subjective nature of taxonomic division. Who exactly, Burnett asks on Sampson's behalf, had decided that

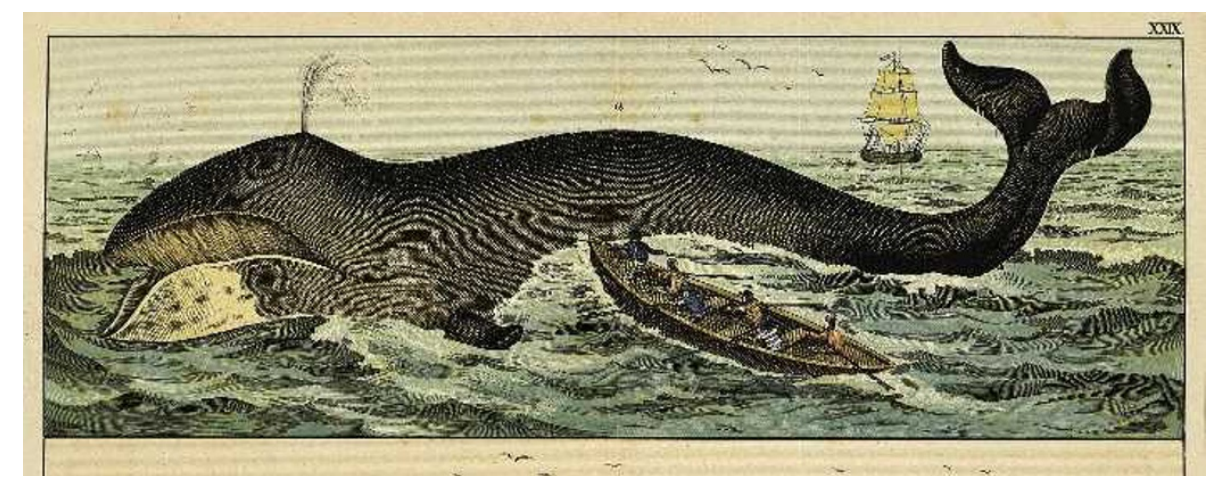

Mammal or fish? The question provoked a notorious court case in the early nineteenth century.

"the intestine preoccupations of comparative anatomy" produced a more accurate taxonomy than one based on visible external characteristics? It's a question as pertinent today as it was in 1818 , with the present generation of taxonomists doing their best to assess the value of different types of data, from morphological measurements to genetic sequences.

Appropriately, Burnett takes the debate out of the courtroom, out of nineteenth century New York, and into more universal territory. Amid much else, the author questions whether Linnaeus really brought order to the taxonomic chaos as rapidly and thoroughly as is commonly assumed. Zoological classification, Burnett suggests, could still be "divided, contentious, even fickle" decades after Linnaeus.

It's a shame that this nuanced history has come too late to feed into this year's tercentennial of Linnaeus's birth. Thankfully, its vivid portrayal of a pre-darwinian world gives a valuable context for anyone intent on Darwin glorification for his bicentenary in 2009. When Mitchill confidently asserted that "a whale is no more fish than a man", he strayed well into what is normally considered Darwinian territory, bridging the sacred void between the animal kingdom and Homo sapiens. It's fascinating to see how this statement (and others like it) played out some 30 years before the publication of On the Origin of Species.

Burnett is right to describe Maurice v. Judd as a "mini-bonanza". Newspapers and periodicals found much in the case to poke fun at. In fact, it would be hard to make this fascinating case a dull read. It's also hard to imagine how anyone could do a better job: he marshals a wealth of primary material - biblical commentaries, school primers, university lecture notes, published taxonomies, sailors' logbooks and private letters.

Burnett curates the abundant quotations with skill and strengthens his thesis with some marvellous contemporary illustrations. His clear writing and delightful detours help build a sense of suspense at the outcome of the trial. All of which makes this serious book an unexpected page-turner.

Henry Nicholls is a editor of Endeavour magazine and author of Lonesome George: The Life and Loves of the World's Most Famous Tortoise (Pan, 2007). 